\title{
An incomplete form of acanthosis nigricans
}

\author{
I. B. SNEDDON AND J. B. M. ROBERTS \\ From The Royal Infirmary, Sheffield
}

EDITORIAL SYNOPSIS The authors report a variation of the clinical picture of acanthosis nigricans in two patients with carcinoma of the stomach.

Acanthosis nigricans is a benign skin condition which, when it appears in adult life, is always associated with an internal carcinoma.

Though uncommon, Curth (1943) was able to review 395 cases reported in the 53 years since the original independent descriptions by Pollitzer and Janovsky in 1890.

The majority of articles on the subject have been dermatological and acanthosis nigricans is now well known to dermatologists. We believe that many surgeons may be unaware of the entity, since references in surgical journals have been few, and we have been unable to find a description of acanthosis nigricans in a selection of surgical textbooks.

It is probable that most patients first seek advice for the skin eruption and, therefore, are referred to a dermatologist; nevertheless, the association with carcinoma of the intestinal tract is so constant that surgical help in investigation and possible laparotomy will always be required. For this reason we will briefly describe the main features of acanthosis nigricans.

Two forms occur, the benign or juvenile type, which appears in childhood, or at latest at puberty, is often familial, and is a harmless skin disorder which is never associated with systemic disease; the adult, or malignant, acanthosis nigricans appears after puberty and before, at the time of, or after, manifestations of carcinoma. It may be impossible to distinguish the benign from the malignant form on clinical and histological grounds and the age of onset may be the only guide. The carcinomata responsible for the skin change may arise in many organs but over $90 \%$ (Curth, 1948) originate within the abdomen, and $61 \%$ (Curth and Aschner, 1959) are gastric in origin. The breast and lung are the usual primary sites of those carcinomata which occur outside the abdominal cavity. Wherever the growth arises, it is usually an adenocarcinoma, always highly malignant with early metastases, and invariably fatal. Recognition of the skin disorder, even if it appears before there are symptoms of carcinoma, has not so far altered the prognosis, metastatic spread having already occurred. The skin lesions subside temporarily after surgical treatment of the primary growth but they reappear with secondary spread (Curth, 1952):

The clinical features of acanthosis nigricans are due to a combination of increased pigmentation and hypertrophy, which produce a dark, velvety thickening of the skin. This pigmented thickening affects mainly the neck, axillae, and groins, though the umbilicus and nipples are also often involved. Changes in the axillae and crural regions were invariably present in 11 cases which came to necropsy (Kierland, 1947). Pedunculated papillomata and flat warts arise in the flexures and on the limbs. Thickening of the skin of the hands and feet and warty overgrowth of the buccal and anal mucosa are nearly always present.

Isolated warty excrescences were present in Pollitzer's original patient and warts on the arms, legs, and trunk were the presenting feature in the patient described by Dingley and Marten (1957). The warts in the latter case were, however, rapidly followed by the usual pigmented hypertrophic changes around the anus and in the mouth. In general, warts are a minor manifestation of acanthosis nigricans.

We record below two examples of a dermatosis associated with carcinoma of the stomach in which warts on the skin of the limbs were the only cutaneous lesions and, in particular, there was complete sparing of the axillae, groins, and mucous membranes.

\section{ILLUSTRATIVE CASES}

CASE 1 A stores manager, aged 46, had undergone a partial gastrectomy for neoplasm of the stomach in September 1958. At that time the glands in the great omentum were involved but no metastases were found in the liver and pelvis. The growth was an anaplastic mucus-secreting carcinoma. He remained fairly well until February 1959 when, at a follow-up examination, a mass was felt in the abdomen. At the same time the 


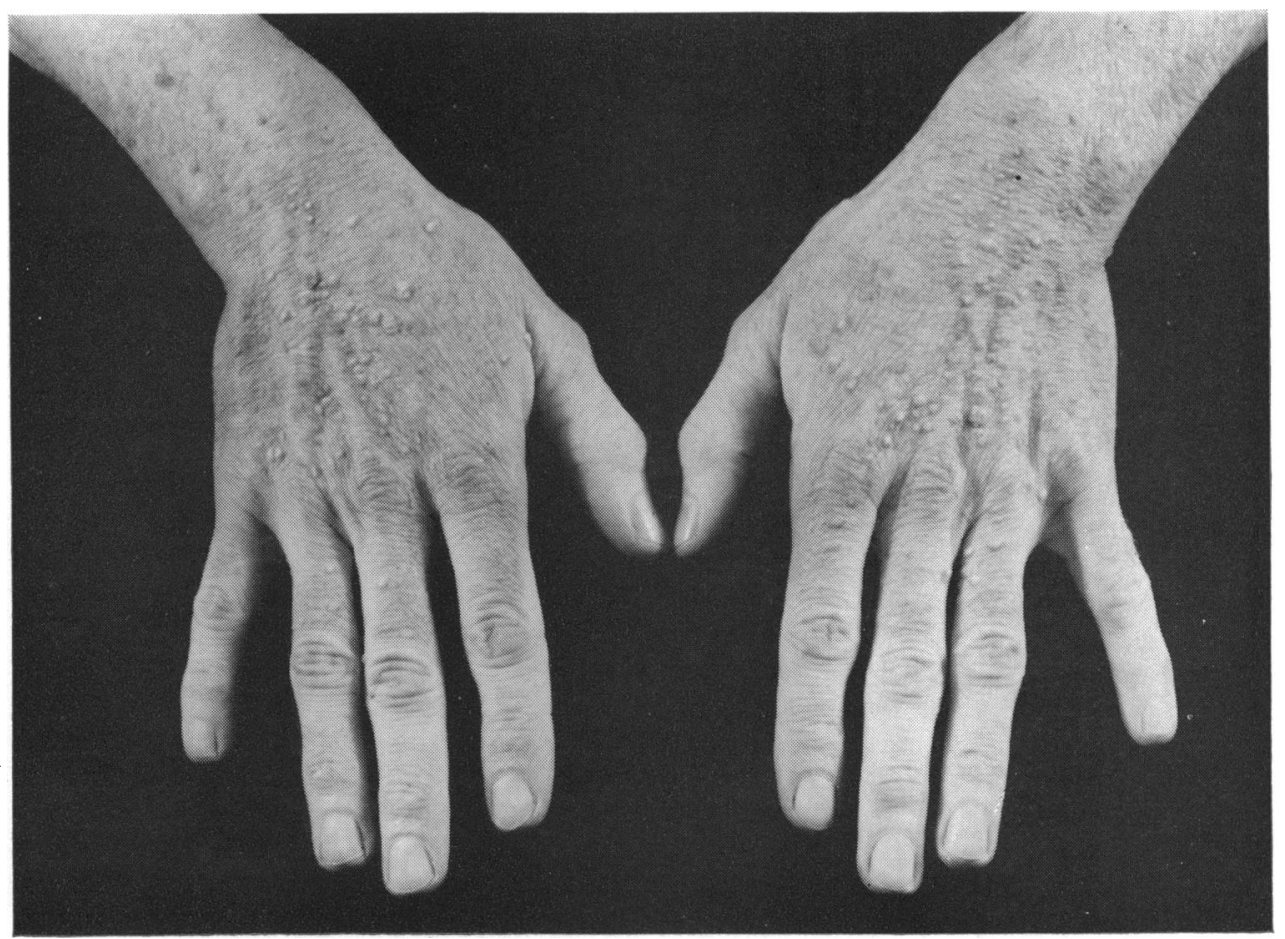

FIG. 1. Hands and wrists of Case 1, showing multiple flat warts.

patient complained of a sudden crop of warts on the backs of the hands, forearms, legs, and thighs. He had had one or two warts on the backs of the hands for a number of years but the sudden and profuse spread had appeared in a few months. The warts were 2 to $5 \mathrm{~mm}$. in diameter, slightly pigmented, and were numbered in hundreds. They were scattered over the backs of the hands and forearms (Fig. 1), the fronts of the legs and thighs, and on the sides of the face and neck. There were none on the trunk and in particular they spared the axillae and groins where there was no increased pigmentation. The mucous membranes were unaffected. A biopsy of the skin of the forearm showed a series of short papillae with keratin plugs between them. The basal layer throughout the section showed slight patchy hyperpigmentation. No melanin-carrying cells were in the dermis and the appearances were considered.consistent with acanthosis nigricans. Laparotomy was carried out on 2 March 1959 and the stomach remnant was found to be infiltrated with growth. The patient died a week later. No necropsy was carried out.

CASE 2 A.O., a driver salesman, aged 58, was referred on 14 November 1960 for treatment of warts on the arms and legs. He had always had a number of pigmented lesions on the arms but during the preceding six months he had noticed an increase in the number and size of the warts. His only other complaint was a lack of energy of several months' duration.
Because of the similarity of this relatively sudden crop of warts to that in Case 1 and a pallid appearance, he was admitted for further investigation. On admission the only physical abnormalities were the skin lesions and the pallor. The warts were distributed over both front and back of all four limbs but spared the trunk except over the shoulders. The most intense crop of warts was on the forearms (Figs. 2 and 3 ) and they became less numerous on the backs of the hands. No changes were present in the skin of the palms and soles nor in the axillae and groins. In appearance the warts were indistinguishable from seborrhoeic warts and they varied in size from a few millimetres up to one centimetre. The larger ones had a dark brown, dry, hyperkeratotic surface; the smaller were smooth and pale fawn. In addition to the warts, on the forearms particularly, there were café au lait pigmented macules. No changes were found in the oral mucosa or on the lips.

Although he did not complain of symptoms of dyspepsia and no signs had been found on abdominal examination, a barium meal showed a filling defect suggestive of a large carcinoma on the lesser curvature of the stomach (Fig. 4). Other investigations were haemoglobin $4 \cdot 1$ grammes per 100 millilitres, red cells $2 \cdot 37$ million.

Histology of skin of the forearms showed an area of acanthosis, papillomatosis, and hyperkeratosis. There was only slight elongation of the rete pegs and pigmentation of the basalis (Fig. 5). 


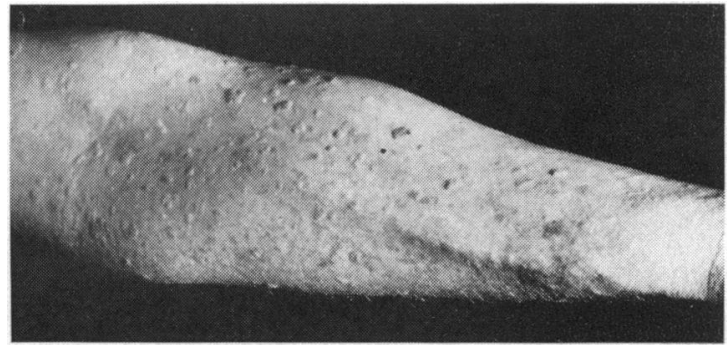

FIG. 2 .

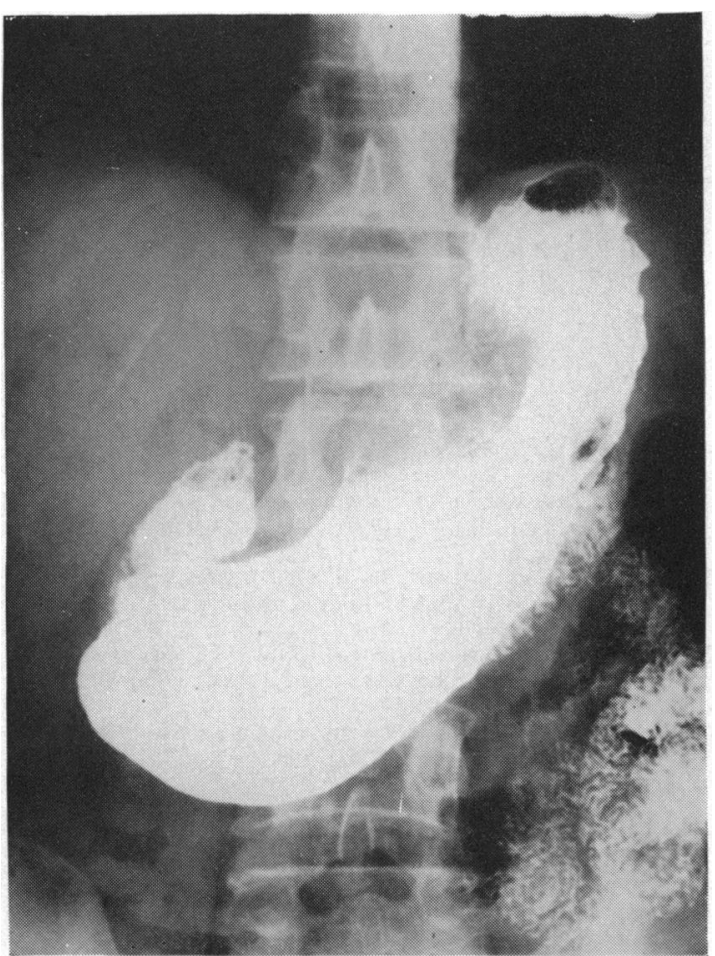

FIG. 4.

FIG. 2. Forearm of Case 2, showing multiple flat warts like seborrhoeic warts with a number of pigmented macules on the skin also.

FIG. 3. Close-up view of the skin of the forearm of Case 2, showing one of the warty excrescences with the surrounding hyperkeratosis and pigmentation.

FIG. 4. Barium meal in Case 2, showing a large filling defect on the lesser curvature of the stomach suggestive of a carcinoma.

FIG. 5. Photomicrograph of portion of warty skin from Case $2 \times 125$. This shows the hyperkeratosis, the formation of papillae, and a slight increase in pigmentation.

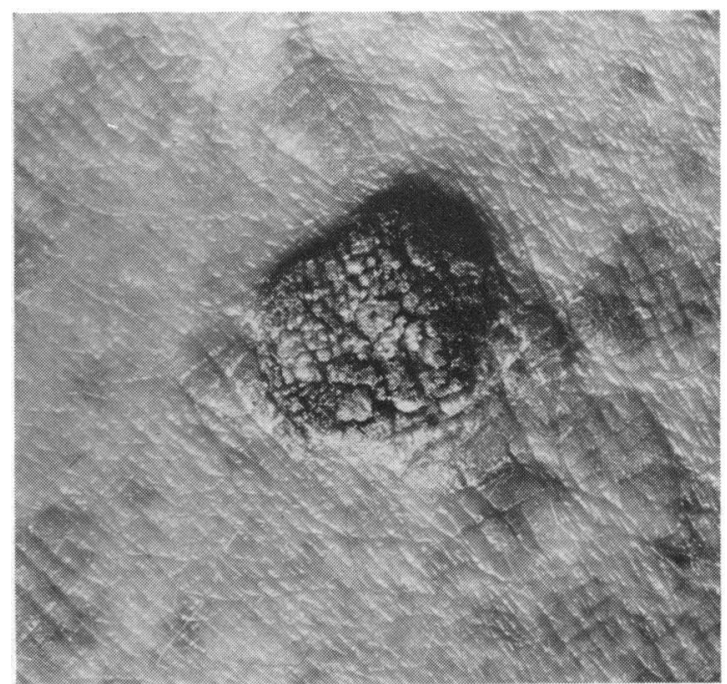

FIG. 3 .

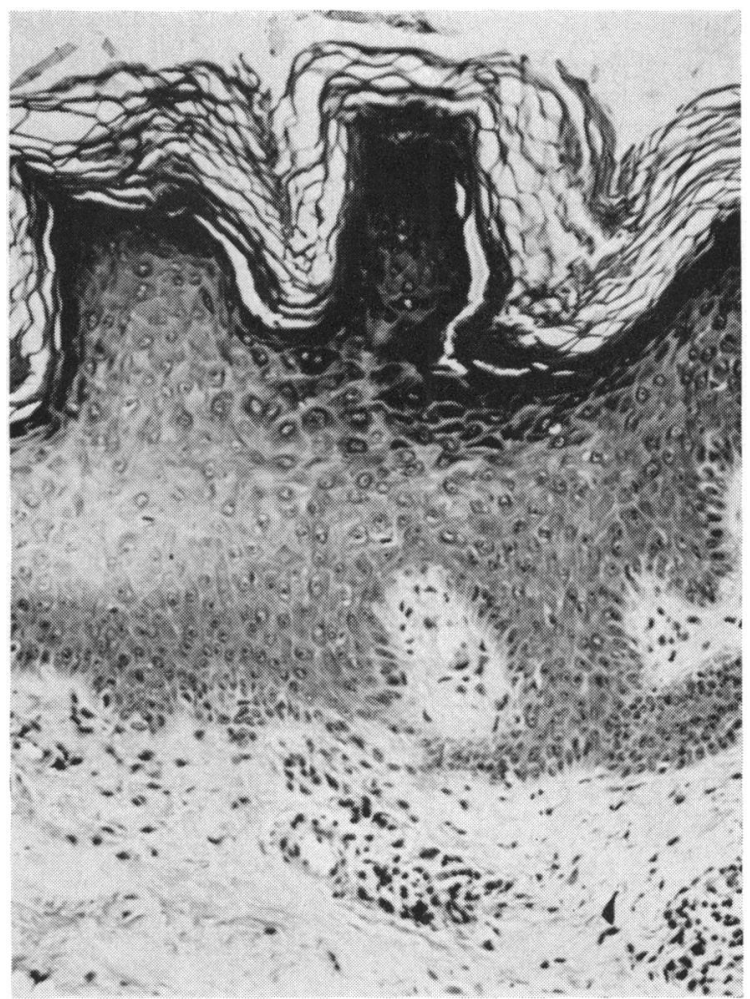

FIG. 5 . 
These findings were consistent with acanthosis nigricans.

Laparotomy revealed a large carcinomatous growth on the anterior wall of the lesser curvature of the stomach with numerous enlarged glands along the left gastric artery (Fig. 6). A subtotal gastrectomy was performed.

The histology of the growth was that of a well differentiated adenocarcinoma of the stomach with metastases in the regional glands. The patient survived only a few months and died at home. No necropsy was performed.

\section{COMMENT}

The occurrence of the sudden outcrop of warts in the first patient when there were signs of metastatic spread from a carcinoma of the stomach suggested that the warts might be a variant of acanthosis nigricans. Warty outgrowths are certainly part of the syndrome of acanthosis nigricans, and were described as marked and discrete in a patient of Forman's (1943) but in his patient there were also the characteristic mucous membrane changes. In view of the absence of mucous membrane changes and pigmentation in the groins and axillae in our first patient it was thought that the warts could be of virus origin and that they had spread because of some failure of the immunity mechanism caused by the advanced carcinoma. However, it was a sufficiently memorable clinical picture to be recalled when the second patient was seen. He sought advice solely for the treatment of the warts which were more numerous and hypertrophic than those of the first patient and quite indistinguishable from seborrhoeic warts (benign basal-celled papillomata). Investigation of the stomach might not have been carried out if we had not seen the first patient, as there were no symptoms referable to the gastrointestinal tract. The appearance of pigmented macules interspersed between the warts in the second patient appeared to exclude virus warts, and, although coincidence cannot be entirely ruled out, the association of this dermatosis with an adenocarcinoma of the stomach on a second occasion makes it most probable that these patients had an incomplete form of acanthosis nigricans.

Amongst the many theories which have been put forward for the association of a benign skin change with internal cancer by far the most reasonable is that of Curth and Aschner (1959). They have postulated that the skin changes are due to a latent genetic abnormality which is only expressed in the presence of a highly malignant adenocarcinoma. We are familiar with the multiplicity of clinical variations of genetic abnormalities of the skin and the occurrence of an incomplete form of acanthosis nigricans is not surprising.

We are grateful to Mr. W. J. Lytle for allowing us to publish an account of these patients who were under his care, and to the Photographic Department of the United Sheffield Hospitals for the photographs.

\section{REFERENCES}

Curth, H. O. (1943). Cancer associated with acanthosis nigricans. Review of literature. Arch. Surg. (Chicago), 47, 517-552.

- (1948). Acanthosis nigricans and its association with cancer. Arch. Derm. Syph. (Chicago), 57, 158-170.

- (1952). Significance of acanthosis nigricans. Ibid., 66, 80-100. , and Aschner, B. M. (1959). Genetic studies on acanthosis nigricans. Ibid., 79, 55-66.

Dingley, E. R., and Marten, R. H. (1957). Adenocarcinoma of the ovary presenting as acanthosis nigricans. J. Obst. Gynaec. Brit. Emp., 64, 898-900.

Forman, L. (1943). Acanthosis nigricans with discrete warts and marked mucous membrane changes in a patient with vitiligo. Proc. roy. Soc. Med., 36, 611 .

Janovsky, V. (1890). Acanthosis nigricans. In International Atlas of Rare Skin Diseases, ed. M. Morris, P. G. Unna, H. Leloir, and L. A. Duhring, No. XI. Voss, Hamburg and Leipzig; Lewis, London.

Kierland, R. R. (1947). Acanthosis nigricans: Analysis of data in 22 cases and a study of its frequency in necropsy material. $J$. invest. Derm., 9, 299-305.

Pollitzer, S. (1890). Acanthosis nigricans. In International Atlas of Rare Skin Diseases, ed. M. Morris, P. G. Unna, H. Leloir, and L. A. Duhring, No. X. Voss, Hamburg and Leipzig; Lewis, London. 